\title{
Solusi Numerik Metode Beda Hingga Aplikasi Excel Untuk Solusi Lendutan Balok Beton Sederhana
}

\author{
Wahyo Hendarto Yoh \\ Fakultas Teknik Program Studi Teknik Sipil Universitas Negeri Malang \\ Email: wahyohendartoyoh@yahoo.co.id
}

\begin{abstract}
The use of worksheets in Excel is one of the tools for learning in solving the mathematical problems. At generaly the solution of mathematical problem ussually is solved by the soft ware aplication, that sure used high level programming languages like FORTRAN, BASIC, C++, MATLAB, etc. However the use of worksheet in Excel rather more familiar than using the software aplication for the students. It is caused the students must be able to know how to write the code program that obtained product the listing program. One of the most problematic on civil engineering is about concrete beam structure deflection. The mathematical analysis simple beam structure deflection is presented by the ordinary differential equation second order non linier and the other name it's called poisson equation. The aim of this article for: (1) To give the learning assistance to the student when they aren't use the soft ware program and beside to rise creation the application spreadsheet as tool for numerical solution by finite difference method on simple beam deflection. (2) To evaluate the error result comparation of numeric solution and analytic solution.(3)To give the understanding about numerical method that accordance with simple beam deflection problem on civil engineering education and mathematical education.
\end{abstract}

Keywords: Fungsi Internal EXCEL, Metode Beda Hingga. Persamaan Garis Elastika.

\section{Pendahuluan}

Penggunaan lembar kerja pada excel merupakan salah satu alat bantu untuk menyelesaikan permasalahan perhitungan matematis pada berbagai bidang aktivitas kita sehari-hari. Dalam bidang teknik sipil di antaranya adalah permasalahan lendutan pada balok sederhana pada dua tumpuan. Permasalahan klasik lendutan pada struktur balok sederhana yang menerima muatan merata dan menahan lentur menghasilkan model matematika yang dinyatakan dalam persamaan diferensial biasa orde dua non linier [1]. Balok beton sederhana adalah elemen struktur beton yang ditumpu pada ujung ujungnya [2]. Balok tersebut berfungsi untuk memikul muatan pelat lantai atau pelat lainnya. Permasalahan lendutan pada balok sederhana ini dimaksudkan untuk menentukan besarnya nilai lendutan maksimum pada tengah tengah bentang balok 
tersebut. Besarnya suatu lendutan balok ditentukan oleh sifat fisik dan mekanik sebagai parameter kerusakan beton yaitu: panjang balok (L), Muatan merata total (W), modulus elastis beton (E), Momen Inersia balok beton (I), Tegangan beton $(\sigma)$, Jari-jari kelengkungan balok beton (R)[3]. Permasalahan lendutan balok sederhana ini me memberikan masukan data untuk analisis matematika yang hasilnya berupa persamaan diferensial orde ke dua persamaan poisson.

Pada umumnya perhitungan matematis digunakan alat bantu dengan aplikasi "soft ware" yang menggunakan bahasa pemrograman seperti fortran, Basic, $\mathrm{C}++$. Namun disisi lain hampir sebagian besar mahasiswa tidak terbiasa menggunakannya, hal ini karena diperlukan pemahaman lebih lanjut tentang kode-kode maupun sintaks bahasa pemrograman tersebut sehingga dapat menghasilkan tampilan "listing program". Bagaimanapun mahasiswa pada umumnya lebih mengenal dan terbiasa dengan lembar kerja excel untuk menyelesaikan permasalahan matematika sehari hari, hal ini karena pada excel telah terdapat berbagai aplikasi fungsi-fungsi internal yang langsung dapat digunakan tanpa kesulitan sintaks dan langsung memberikan luaran hasilnya. Karena itu penggunaan lembar kerja excel bagi mahasiswa akan menjadi alat bantu awal yang bermanfaat dalam memahami solusi numerik yang berbasis pada berbagai "soft ware" program yang ada [4],[5]. Oleh karena itu kajian dalam artikel ini bertujuan : (1) Untuk memberikan penjelasan dan pemahaman bagi mahasiswa dalam mempelajari metode numerik ketika tidak menggunakan bahasa pemrograman. Disamping itu membangkitkan kreativitas penggunaan excel sebagai alat bantu mahasiswa dalam mendapatkan solusi numerik persamaan garis elastika pada balok sederhana dua tumpuan menggunakan metode beda hingga. (2) Untuk mengetahui perbandingan hasil solusi numerik dan solusi analitik pada persamaan diferensial tersebut. (3) Untuk memberikan pemahaman bagi mahasiswa dalam menggunakan dan memilih metode numerik yang sesuai dengan permasalahan lendutan balok beton sederhana.

\section{Data dan Metode}

\subsection{Persamaan Garis Elastika}

Persamaan garis elastika adalah hasil analisis matematis yang memberikan model matematika pada permasalahan lendutan struktur balok. Persamaan garis elastka dibangun oleh parameter fisik dan mekanik yaitu: panjang balok (L), Muatan merata total (W), modulus elastis beton (E), Momen Inersia balok beton (I), Tegangan beton $(\sigma)$, Jari-jari kelengkungan balok beton $(\mathrm{R})[3]$. Analisis matematis pada permasalahan lendutan balok dapat diturunkan dari elemen balok menerima beban lentur menurut persamaan sebagai berikut [2]:

$$
\frac{\sigma}{Y}=\frac{M}{I}=\frac{E}{R}
$$




$$
\frac{1}{R}=\frac{d^{2} y / d x^{2}}{\left[1+(d y / d x)^{2}\right]^{3 / 2}}
$$

Pada lendutan yang kecil diperlukan dalam aplikasi perancangan struktur maka $(d y / d x)^{2}$ diabaikan, karena itu (2) dapat dinyatakan oleh:

$$
\frac{1}{R}=\frac{d^{2} y}{d x^{2}}
$$

Akan tetapi $\frac{M}{I}=\frac{E}{R}$, karena itu (3) memberikan:

$$
\frac{d^{2} y}{d x^{2}}=\frac{M}{E I}
$$

yang dikenal sebagai persamaan diferensial garis elastika pada balok yang menahan lentur. Permasalahan lendutan Balok beton sederhana (Gambar 1) terdapat parameter fisik dan mekanik yang akan digunakan sebagai input untuk solusinya.

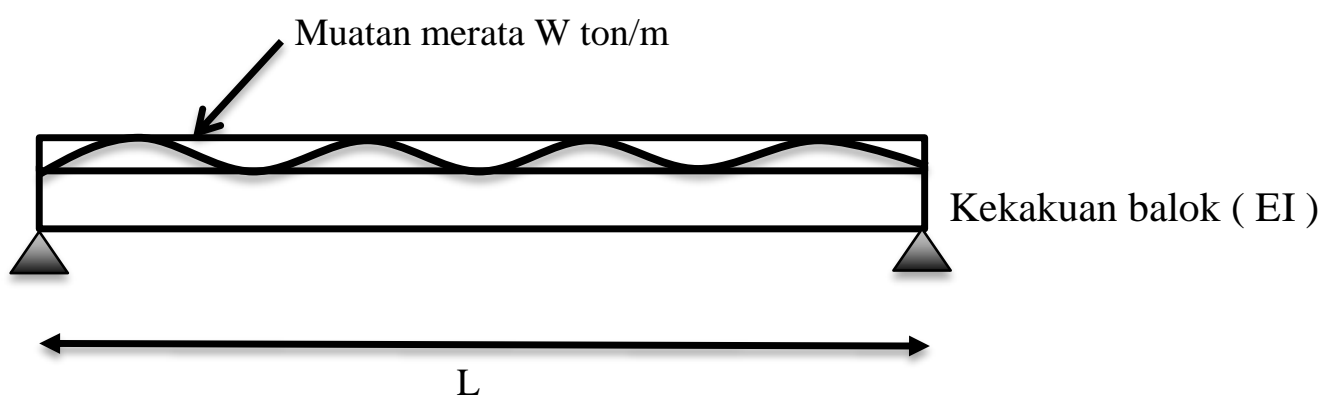

Gambar 1. Balok beton sederhana

Panjang balok beton $\mathrm{L}=6,0$ meter, Muatan merata sepanjang balok $\mathrm{W}=200,0 \mathrm{~kg} / \mathrm{m}$, Modulus elasitisitas $\mathrm{E}=2 \times 10^{9} \mathrm{~kg} / \mathrm{m}^{2}$, Momen inersia balok beton $\mathrm{I}=1 \times 10-{ }^{4} \mathrm{~m}^{4}$. Besar momen lentur yang bekerja pada balok sederhana memberikan persamaan:

$$
M=\frac{w x^{2}}{2}-\frac{w L x}{2}
$$

dari (4) dan (5) memberikan persamaan garis elastika yaitu:

$$
\frac{d^{2} y}{d x^{2}}=\frac{w x^{2}}{2 E I}-\frac{w L x}{2 E I}
$$

dengan menggunakan input parameter fisik dan mekanik pada (6) maka memberikan persamaan diferensial sebagai berikut:

$$
\frac{d^{2} y}{d x^{2}}=\frac{200 x^{2}}{2 \cdot\left(2 \cdot 10^{9}\right) \cdot 10^{-4}}-\frac{200 \cdot 6,0 x}{2 \cdot\left(2 \cdot 10^{9}\right) \cdot 10^{-4}}
$$


Dari (7) disederhanakan dan memberikan model matematika pada permasalahan lendutan balok beton sederhana yang dinyatakan dalam (8) yaitu persamaan diferensial orde kedua non linier, dinamakan juga persamaan poisson.

$$
y^{\prime \prime}=\left[100 x^{2}-300 x\right] 10^{-5}
$$

Solusi analitis pada kondisi batas $x=\frac{L}{2} \quad$ untuk $\frac{d y}{d x}(0)=0 \quad$ dan $\mathrm{y}(0)=0$ pada (6) memberkan rumus lendutan sepanjang balok yaitu:

$$
y(x)=\frac{w}{24 E I}\left[x^{4}-2 L x^{3}+L^{3} x\right]
$$

\subsection{Solusi Numeris Metode Beda Hingga}

Solusi numeris pada persamaan diferensial orde dua (8) adalah memiliki bentuk umum yaitu:

$$
\frac{d^{2} y}{d x^{2}}=f(x)
$$

Jika solusi numerik pada domain $[0,1]$ untuk nilai awal $y(0)=0$ dan $y(1)=0$ maka persamaan beda hingga terpusat diferensial orde dua adalah [6]:

$$
\frac{d^{2} y}{d x^{2}}=\frac{y_{i-1}-2 y_{i}+y_{i+1}}{h^{2}}
$$

Pada (10) jika diambil solusi untuk domain $[0, n]$ dengan nilai awal $\mathrm{Y}(0)=0$ nilai akhir $\mathrm{Y}(\mathrm{n})=0$ maka dari (10) dan (11) memberikan:

$$
\frac{y_{i-1}-2 y_{i}+y_{i+1}}{h^{2}}=h^{2} f i(x)
$$

$$
\text { Untuk } \mathrm{i}=1,2,3, \ldots \ldots \ldots \ldots \ldots(\mathrm{n}-1)
$$

Dimana sepanjang balok pada sumbu $x$ terdapat titik simpul seperti pada gambar 2 .

Di bawah ini dengan panjang $h=x_{i+1}-x_{i}$

\section{Titik Simpul}

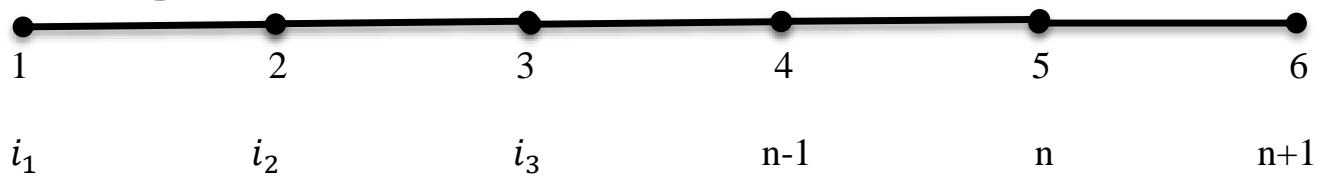

Gambar 2. Titik simpul pada sumbu $\mathrm{x}$

Persamaan (12) pada simpul simpul adalah:

Untuk i $=1$ memberikan $y_{0}-2 y_{1}+y_{2}=h^{2} f_{1}$

Untuk i $=2$ memberikan $y_{1}-2 y_{2}+y_{3}=h^{2} f_{2}$ 
Untuk i $=3$ memberikan $y_{2}-2 y_{3}+y_{4}=h^{2} f_{3}$

Untuk $\mathrm{i}=\mathrm{n}$ memberikan $y_{n-1}-2 y_{n}+y_{n+1}=h^{2} f_{n}$

Persamaan (13) memberikan persamaan linier simultan dalam bentuk matrik seperti berikut:

$$
\left[\begin{array}{cccc}
-2 & 1 & 0 & 0 \\
1 & -2 & 1 & 0 \\
0 & 1 & -2 & 1 \\
0 & 0 & 0 & -2
\end{array}\right]\left[\begin{array}{l}
y_{1} \\
y_{2} \\
y_{3} \\
y_{n}
\end{array}\right]=h^{2}\left[\begin{array}{l}
f_{1} \\
f_{2} \\
f_{3} \\
f_{n}
\end{array}\right]
$$

Persamaan (14) memberrikan solusi $y_{1}, y_{2}, y_{3}, y_{n}$. yang menyatakan lendutan di titik simpul 1, 2, 3, hingga $n$.

\subsection{Solusi Analitis}

Dengan menggunakan data masukan sifat fisik dan mekanik dan metode langsung integral dua kali pada persamaan diferensial orde dua persamaan poisson (8) maka memberikan solusi persamaan diferensial sebagai Solusi analitis yang dinyatakan dalam (9). Dari persamaan tersebut dapat dihitung besarnya lendutan balok beton pada tiap nilai $\mathrm{x}$ spanjang balok, untuk itu perhitungan lendutan sepanjang balok mengggunakan lembar kerja Excel.

\subsection{Aplikasi}

Untuk metode penyelesaian permasalahan lendutan balok sederhana digunakan aplikasi EXCEL sebagai alat penghitung solusi numerik metode beda hingga. Karena itu diperlukan suatu model Tabel pada lembar kerja Excel yang sesuai untuk keperluan tersebut. Dari berbagai persamaan tersebut diatas akan memberikan parameter masukan dan hasil luaran berupa solusi numerik yang dituliskan pada lembar kerja Excel seperti pada Tabel berikut ini:

Tabel 1. Model Tabel Solusi Numerik Excel

\begin{tabular}{|l|l|}
\hline Data Masukan & $y^{\prime \prime}=\left[100 x^{2}-300 x\right] 10^{-5}$ \\
\hline Nilai awal & $\mathrm{y}(0)=0 \quad \mathrm{y}(\mathrm{n})=0$ \\
\hline Kondisi batas & $y^{\prime}(0)=0$ \\
\hline jarak interval & $\mathrm{h}=0,60$ \\
\hline Absis & $x_{0}=0 ; x_{1}=0,60 ; x_{2}=1,20 ; \ldots \ldots . x_{11},=6,0$ \\
\hline Luaran & $y\left(\frac{L}{2}\right)$ \\
\hline
\end{tabular}


Dengan memperhatikan variabel parameter yang terdapat pada (10) sampai (14) akan memberikan panduan pada pembentukkan Tabel untuk proses perhitungan dalam penggunaan Excel. Hal ini tampak pada Tabel 2. hingga Tabel 5.

Tabel 2. Notasi Numerik Beda Hingga

\begin{tabular}{|c|c|c|c|}
\hline$i$ & $y_{i-1}$ & $-2 y_{i}$ & $y_{i+1}$ \\
\hline 1 & $y_{0}$ & $-2 y_{1}$ & $y_{2}$ \\
\hline 2 & $y_{1}$ & $-2 y_{2}$ & $y_{3}$ \\
\hline 3 & $y_{2}$ & $-2 y_{3}$ & $y_{4}$ \\
\hline 4 & $y_{3}$ & $-2 y_{4}$ & $y_{5}$ \\
\hline 5 & $y_{4}$ & $-2 y_{5}$ & $y_{6}$ \\
\hline 6 & $y_{5}$ & $-2 y_{6}$ & $y_{7}$ \\
\hline 7 & $y_{6}$ & $-2 y_{7}$ & $y_{8}$ \\
\hline 8 & $y_{7}$ & $-2 y_{8}$ & $y_{9}$ \\
\hline 9 & $y_{8}$ & $-2 y_{9}$ & $y_{10}$ \\
\hline 10 & $y_{9}$ & $-2 y_{10}$ & $y_{11}$ \\
\hline 11 & $y_{10}$ & $-2 y_{11}$ & $y_{12}$ \\
\hline
\end{tabular}

Tabel 3. Matriks Indek Beda Hingga

\begin{tabular}{|c|c|c|c|c|c|c|c|}
\hline $\mathrm{i} \longrightarrow \mathrm{y}$ & $y_{1}$ & $y_{2}$ & $y_{3}$ & $y_{4}$ & $\ldots \ldots \ldots . .$. & $y_{i-1}$ & $y_{i}$ \\
\hline 1 & -2 & 1 & 0 & 0 & ............. & 0 & 0 \\
\hline 2 & 1 & -2 & 1 & 0 & ........... & 0 & 0 \\
\hline 3 & 0 & 1 & -2 & 1 & ............ & 0 & 0 \\
\hline ................ & ............ & ........... & .......... & ............ & ............ & ........... & ........... \\
\hline$(n-1)$ & 0 & 0 & 0 & & 1 & -2 & 1 \\
\hline $\mathrm{n}$ & 0 & 0 & 0 & 0 & 0 & 1 & -2 \\
\hline
\end{tabular}

Tabel 4. Matriks Beda Hingga $=[\mathrm{A}]$

\begin{tabular}{|c|c|c|c|c|c|c|c|}
\hline-2 & 1 & 0 & 0 & 0 & $\ldots \ldots \ldots \ldots$ & 0 & 0 \\
\hline 1 & -2 & 1 & 0 & 0 & $\ldots \ldots \ldots \ldots$ & 0 & 0 \\
\hline 0 & 1 & -2 & 1 & 0 & $\ldots \ldots \ldots \ldots$ & 0 & 0 \\
\hline 0 & 0 & 1 & -2 & 1 & $\ldots \ldots \ldots \ldots$ & 0 & 0 \\
\hline$\ldots \ldots \ldots \ldots$. & $\ldots \ldots \ldots \ldots$ & $\ldots \ldots \ldots \ldots$ & $\ldots \ldots \ldots \ldots$ & $\ldots \ldots \ldots \ldots$ & $\ldots \ldots \ldots \ldots$ & $\ldots \ldots \ldots \ldots$ & $\ldots \ldots \ldots \ldots$ \\
\hline 0 & 0 & 0 & 0 & 0 & $\ldots \ldots \ldots .$. & -2 & 1 \\
\hline 0 & 0 & 0 & 0 & 0 & $\ldots \ldots \ldots .$. & 1 & -2 \\
\hline
\end{tabular}


Tabel 5. Matriks $h^{2} f\left(x_{i}\right)=[\mathrm{B}]$

\begin{tabular}{|c|c|}
\hline$x_{i}$ & $h^{2} f\left(x_{i}\right)$ \\
\hline$x_{1}$ & $h^{2} f\left(x_{1}\right)$ \\
\hline$x_{2}$ & $h^{2} f\left(x_{2}\right)$ \\
\hline$\ldots \ldots$ & $\ldots \ldots \ldots \ldots \ldots$ \\
\hline$x_{11}$ & $h^{2} f\left(x_{11}\right)$ \\
\hline
\end{tabular}

Dari Tabel-Tabel pada lembar kerja Excel dari matriks seperti diatas, maka dengan menggunakan fungsi internal Excel untuk perkalian matriks antara matrik invers A dengan matriks B akan memberikan solusi numerik metode tersebut. Demikian pula pada solusi analitis dapat dibangun Tabel untuk lembar kerja Excel sebagai berikut:

Tabel 6. Model Tabel Solusi Analitis Excel

\begin{tabular}{|l|l|}
\hline Solusi numerik & $y(x)=\frac{w}{24 E I}\left[x^{4}-2 L x^{3}+L^{3} x\right]$ \\
\hline Jarak interval & $\mathrm{h}=0,60$ \\
\hline Absis & $x_{0}=0 ; x_{1}=0,60 ; x_{2}=1,120 ; \ldots . . x_{11}=6,0$ \\
\hline Luaran & $y(3)$, dan $y(n)$ \\
\hline
\end{tabular}

\section{Hasil dan Pembahasan}

Hasil perhitungan menggunakan lembar kerja Excel memberikan solusi analitis dan solusi numerik yang dapat dilihat pada Tabel 7. seperti berikut:

Tabel 7. Hasil Solusi Numerik dan Solusi Eksak

\begin{tabular}{|c|c|c|c|c|c|}
\hline \multicolumn{3}{|c|}{$\begin{array}{c}\text { Solusi numerik } \\
\text { metode beda hingga }\end{array}$} & \multicolumn{2}{c|}{ Solusi eksak } & $\begin{array}{l}\text { Selisih } \\
\text { kesalahan }\end{array}$ \\
\hline $\mathrm{X}_{\mathrm{i}}$ & $\begin{array}{c}\text { Lendutan } \\
\mathrm{y}(\mathrm{m})\end{array}$ & $\begin{array}{c}\text { Lendutan } \\
\mathrm{y}(\mathrm{cm})\end{array}$ & $\begin{array}{c}\text { Lendutan y } \\
(\mathrm{m})\end{array}$ & $\begin{array}{c}\text { Lendutan y } \\
(\mathrm{cm})\end{array}$ & $/ \varepsilon /(\mathrm{m})$ \\
\hline 0,00 & $-0,0012$ & $-0,12$ & 0,0000 & 0,00 & 0,0012 \\
\hline 0,60 & $-0,0024$ & $-0,24$ & $-0,0053$ & $-0,53$ & $-0,0029$ \\
\hline 1,20 & $-0,0041$ & $-0,41$ & $-0,0100$ & $-1,00$ & $-0,0059$ \\
\hline 1,80 & $-0,0066$ & $-0,66$ & $-0,0137$ & $-1,37$ & $-0,0072$ \\
\hline 2,40 & $-0,0098$ & $-0,98$ & $-0,0161$ & $-1,61$ & $-0,0062$ \\
\hline 3,00 & $-0,0136$ & $-1,36$ & $-0,0169$ & $-1,69$ & $-0,0033$ \\
\hline 3,60 & $-0,0174$ & $-1,74$ & $-0,0161$ & $-1,61$ & 0,0013 \\
\hline 4,20 & $-0,0204$ & $-2,04$ & $-0,0137$ & $-1,37$ & 0,0067 \\
\hline 4,80 & $-0,0216$ & $-2,16$ & $-0,0100$ & $-1,00$ & 0,0116 \\
\hline 5,40 & $-0,0197$ & $-1,97$ & $-0,0053$ & $-0,53$ & 0,0144 \\
\hline 6,00 & $-0,0131$ & $-1,31$ & 0,0000 & 0,00 & 0,0131 \\
\hline
\end{tabular}


Hasil solusi numerik metode beda hingga pada Gambar 2. menunjukkan bahwa pada ujung kiri balok besar lendutan adalah 0,0012 $\mathrm{m}$ dan solusi eksak memberikan lendutan sebesar $0,0000 \mathrm{~m}$, karena itu terdpat kesalahan sebesar $\varepsilon=0,0012$. Akan tetapi jika digunakan 2 angka signifikan maka solusi numerik memberikan lendutan diujung kiri balok adalah $0,0000 \mathrm{~m}$, hal ini memenuhi nilai awal untuk $\mathrm{y}(0)=0$ pada persamaan garis elastika dan memenuhi solusi eksak yang terdapat nilai lendutan adalah 0,0000 m.[2] Selanjutnya solusi eksak pada ujung balok kanan memberikan lendutan sebesar sebesar 0,0000 m sehingga memenuhi persamaan garis elastika nilai akhir $\mathrm{y}(6)=0$, Sedangkan untuk solusi numerik untuk y(6) memberikan lendutan sebesar $0,0131 \mathrm{~m}$ terdapat kesalahan sebesar $0,0131 \mathrm{~m}$

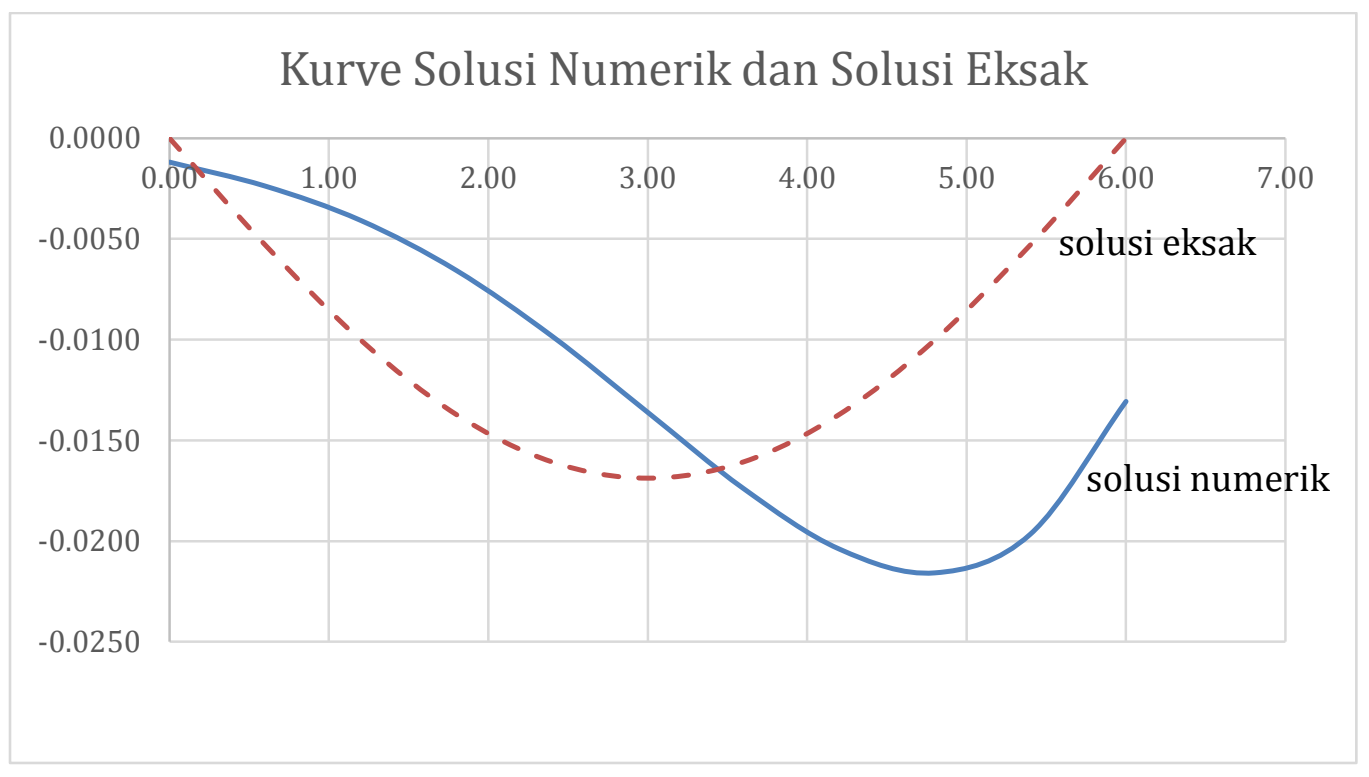

Gambar 2. Hasil Solusi Numerik dan Solusi Eksak

terhadap solusi eksak. Pada tengah-tengah bentang balok solusi numerik memberikan lendutan sebesar -0,0136 m dan solusi eksak memberikan lendutan sebesar 0,0169 hal ini sesuai dengan permasalahan nilai awal $\mathrm{y}(0)=0 ; \mathrm{y}(\mathrm{n})=0$, dan kondisi batas $y^{\prime}(0)=0$ dari persamaan garis elastika $y^{\prime \prime}=\left[100 x^{2}-300 x\right] 10^{-5}$ pada rumus lendutan balok sederhana memikul muatan merata yaitu: $y=\frac{5 w L^{4}}{384 E I}$ [2]. Ditinjau dari kesesuaian metode, solusi numerik metode beda hingga adalah relevan digunakan pada masalah balok sederhana, karena kondisi batas pada balok sederhana memenuhi analisis numerik metode beda hingga. Hal ini memberikan pemahaman bahwa untuk permasalahan lendutan balok cantilever tidak relevan jika menggunakan metode beda hingga ataupun metode lainnya. Dari aplikasi Excel dalam hal ini diperlukan Tabel- 
Tabel yang memuat variabel fisik dan mekanik sebagai masukan data perhitungan dan sekaligus juga memuat luaran hasil perhitungan. Selanjutnya dengan menggunakan fungsi internal Excel seperti perkalian matriks, invers matriks, dan lainnya dimana sebagian besar mahasiswa sudah memahaminya.

\section{Simpulan dan Saran}

Simpulan pada artikel ini yaitu:

1) Solusi numerik metode beda hingga untuk permasalahan lendutan balok sederhana dapat diselesaikan tanpa menggunakan bahasa pemrograman, dalam hal ini digunakan fungsi internal Excel.

2) Hasil solusi numerik metode beda hingga memberikan nilai lendutan yang sama dengan solusi eksak jika digunakan dua angka signifikan.

3) Jika digunakan solusi numerik lainnya maka solusi numerik metode hingga adalah relevan untuk menyelesaikan permasalahan lendutan balok sederhana.

\section{Daftar Pustaka}

[1] Tarsicio Beleandez at.al "Numerical and Experimental Analysis of a Cantilever Beam a Laboratory Project to Introduce Geometric Nonlinearity in Mechanics of Materials" Int. J. Engng Ed. Vol. 19, No. 6, pp. 885-892, 2003.

[2] Yuan-Yu Hsieh, Suryadi, Teori Dasar Struktur, Erlangga, Jakarta, 1985.

[3] Wahyo Hendarto Yoh, "Evaluasi Beban Hancur Silinder Beton Menggunakan Pendekatan Analisis Dimensional Metode Rayleigh", Prosiding Seminar Nasional Teknik Sipil Program Pasca Sarjana Universitas Udayana, hal. Str - 167- 171, 2015.

[4] Van Wyk, Christopher J. "Using Spreadsheets to Learn Numerical Methods", Spreadsheets in Education (eJSiE): Vol. 2: Iss. 1, Article 9. 2006.

[5] Jacek Uziak, Spreedsheet Aplication in Beam Bending Calculations, World Transaction on Engineering and Technology Education, Vol. 12, No.3, 2014.

[6] Joe D. Hoffman, Numerical Methods for Engineers and Scientists, Marcel Dekker Inc, New York, 2001 